\title{
Joining of CFRT-steel hybrid parts via hole-forming and subsequent pin caulking
}

\author{
David Römisch $^{1}\left[\right.$ D Julian Popp ${ }^{2} \cdot$ Dietmar Drummer $^{2} \cdot$ Marion Merklein $^{1}$
}

Received: 15 October 2021 / Accepted: 29 November 2021 / Published online: 23 December 2021

(c) The Author(s) 2021

\begin{abstract}
In times of increasing global warming, the awareness of the necessity for significant $\mathrm{CO}_{2}$ reduction is growing. Especially in the transport and aerospace sector, lightweight construction has potential to achieve emission reduction goals by reducing the overall vehicle weight. Thereby, adding lightweight fibre-reinforced composites to materials such as steel and aluminium is used to achieve weight savings. Furthermore, continuous-fibre-reinforced thermoplastics (CFRTs) begin to replace more traditional thermoset thermoplastics due to their easier bulk production and uncomplicated storage. Hybrid parts often consist of a CFRT and a higher strength metal component. Here, the joining process poses the main challenge, due to different chemical and physical properties of the components. In the current state of the art, riveted and bolted joints are commonly used, leading to increased weight due to auxiliary elements and requiring precise bolt holes often destroying load-bearing fibres. Joining with cold formed pin structures is an innovative and versatile joining process, which avoids the need for auxiliary elements. These pins are subsequently inserted in warm formed holes in the CFRT component and then caulked to create a form-fitting hybrid joint. To obtain a fundamental understanding of this joining process, hole-forming and pin-caulking, are investigated in this study. First, the hole-forming with IR-radiation is investigated with regard to suitable process parameters and resulting fibre morphology. The formed holes are consequently mechanically characterized. Second, the caulking-process is investigated by iteratively upsetting a pin and subsequently measuring the geometry. Based on these findings two different suitable caulking degrees are defined and samples for mechanical as well as microscopic investigations are manufactured. The created joints are first investigated via micro-sections and reflected light microscopy to identify possible damage in the CFRT component, which can result from the pin caulking process. Second, a mechanical characterisation under shear load as well as pin extraction loads normal to the sample surface is conducted and the normal load tests are compared with the bearing strength of CFRT samples.
\end{abstract}

Keywords Hybrid joints $\cdot$ Pin joining $\cdot$ Multi-material-systems $\cdot$ Pin extrusion $\cdot$ Organo sheet $\cdot$ Continuous fibre reinforced thermoplastics

\section{Introduction}

In times of climate change and the increasing urge to reduce carbon dioxide emissions, lightweight materials offer a great potential for a sustainable future, especially in the transport sector. Continuous fibre reinforced thermoplastics (CFRTs) often referred to as organo-sheets offer a high potential in

David Römisch

david.roemisch@fau.de

1 Institute of Manufacturing Technology, Friedrich-AlexanderUniversität Erlangen-Nürnberg, Erlangen, Germany

2 Institute of Polymer Technology, Friedrich-Alexander-Univer sität Erlangen-Nürnberg, Erlangen, Germany lightweight applications due to their favourable strengthand stiffness to weight ratio and their processability in large volume manufacturing [1]. While high stiffness values can already be achieved with short fibre lengths [2], endless fibres show superior properties in ultimate strength [3] as well as impact properties [4]. Compared to thermoset composites, which are typical competitors in high performance lightweight applications, CFRTs have a number of advantages. The solidification process is induced by physical processes (cooling) instead of chemical reactions (curing) which allows significantly reduced cycle times in production. Furthermore, the shelf life of thermoplastics is virtually unlimited and cooling is not required while storing [5]. 
However, despite these advantages, under certain operational conditions, such as elevated temperatures above the melting- (semi crystalline matrix) or glass transition temperature (amorphous matrix) or applications with high abrasive wear, parts manufactured from CFRTs can reach their limits. One promising technology to address these limitations of CFRTs is the development of multimaterial parts, which combine a CFRT component with a metal component such as higher strength steel. Due to dissimilar physical properties (e.g. thermal expansion coefficient) and chemical incompatibilities, the joining process is the major challenge of this approach.

In state of the art composite to metal joining, bolted and riveted joints that create a form- and/or force fitting connection are commonly used. Despite their widely spread application, these technologies have the disadvantage of added weight [6] to the created structure due to the required rivet or bolt which contradicts the idea of lightweight construction. Furthermore, the required hole for the joining process is oftentimes created via cutting technologies, such as drilling [7], which destroy load bearing fibres and consequently weaken the composite. In $[8,9]$ the warm hole-forming of relatively large holes in CFRT components is described which avoids the destruction of load bearing fibres. A promising approach to join CFRT-steel hybrid parts is the use of metallic pins, which are pushed through the locally heated CFRT component and are consequently caulked to create an undercutting joint as shown on the example of additively manufactured pins in [10] and cold formed pins in [11]. Despite a wide insight in this joining technology given in the cited studies, no systematic investigation of the resulting fibre orientations and the caulking process and its influence on the joint strength can be found in the current state of the art. Behind this background, the hole forming process of small holes will first be investigated in the present work using glass fibre reinforced thermoplastics with a unidirectional fabric as a pre-stage to joining by caulking. In particular, the fibre rearrangement during the hole forming process and the melting zone will be investigated in more detail. Furthermore, the evolution of the pin geometry during continuous upsetting is analysed by incremental upsetting and an iterative geometric measurement of a pin structure formed by cold extrusion. In this way, two suitable upsetting degrees are identified for joining the steel/CFRT samples. These are used in the subsequent step to investigate their influence on the mechanical properties during caulking by testing the joints using the cross tension test and tensile shear test. Furthermore, the joints are analysed with regard to possible damage to the matrix and fibres during the joining process using micrographs.

\section{Material and methods}

\subsection{Glass fibre-polypropylene (PF-PP) samples}

In order to be able to control the material properties, the material used in this study has been manufactured at the NMF GmbH, Fürth, Germany, via the interval hot pressing process. As matrix material a polypropylene type $\mathrm{BJ} 100 \mathrm{HP}$ from Borealis AG, Vienna, Austria is used, which is a special low-viscosity polypropylene (PP) compound developed specifically for applications with glass fibre reinforcements. As a fibre material a customized quasi unidirectional non-crimp glass fibre fabric manufactured by Saertex GmbH \& Co. KG, Saerbek, Germany is utilized. The non-crimp fabric is manufactured with an areal weight of $283 \mathrm{~g} / \mathrm{m}^{2}$ of E-glass fibre rovings with a grammage of 300 tex in fill direction and $1 \mathrm{~g} / \mathrm{m}^{2}$ of E-glass rovings with a grammage of 68 tex in warp direction. A polyester sewing thread with a grammage of 76 dtex is used with an areal weight of $12 \mathrm{~g} / \mathrm{m}^{2}$ to secure the fabric. The total areal weight of the non-crimp fabric is specified to $296 \mathrm{~g} /$ $\mathrm{m}^{2}$. In total 4 layers of the described non-crimp fabric are stacked together and impregnated with the matrix material resulting in a thickness of approximately one millimetre and a fibre volume content of approximately $45 \%$. Preliminary Differential scanning calorimetry (DSC) tests of the resulting material with a heating rate of $10 \mathrm{~K} / \mathrm{min}$ show a melt peak temperature of $164.7 \pm 0.76{ }^{\circ} \mathrm{C}$ and a crystallisation peak of $121.9 \pm 1.12{ }^{\circ} \mathrm{C}$ as an average of nine measurements. The measured density of the material is $1.61 \pm 0.02 \mathrm{~g} / \mathrm{cm}^{3}$ as an average of three measurements and the filler share is measured via ashing at a maximum temperature of $625{ }^{\circ} \mathrm{C}$ to $65.9 \pm 0.84 \mathrm{wt} . \%$. Preliminary measurements of the thermal diffusivity in all three directions with a Nano Flash LFA 447 (NETZSCH Gerätebau $\mathrm{GmbH}$, Selb, Germany) give the following results as an average of seven measurements. In fibre direction (y): $0.297 \pm 0.009 \mathrm{~mm}^{2} / \mathrm{s}$. Perpendicular to the fibre direction (x): $0.255 \pm 0.005 \mathrm{~mm}^{2} / \mathrm{s}$. In Thickness direction of the sample (z): $0.205 \pm 0.007 \mathrm{~mm}^{2} / \mathrm{s}$.

The material used for the extrusion of the pin structures is a HCT590X $+\mathrm{Z}$ dual phase steel (DP600) with a sheet thickness of $t_{0}=1.5 \mathrm{~mm}$ from Salzgitter Flachstahl GmbH, Salzgitter. The chemical composition of the material is listed in Table 1. The cold-rolled and galvanised DP600 is frequently used in the automotive industry for structural components in car body construction due to its good formability combined with high strength, which results from the martensitic grain structure embedded in the ferritic matrix. 
Table 1 Chemical composition of the HCT590X + Z (DP600) used for the extrusion of the pin structures in weight percent [12]

\begin{tabular}{lllllllll}
\hline Material & $\mathrm{C}$ & $\mathrm{Si}$ & $\mathrm{Mn}$ & $\mathrm{P}$ & $\mathrm{S}$ & $\mathrm{Al}_{\text {total }}$ & $\mathrm{Cr}+\mathrm{Mo}$ & $\mathrm{Nb}+\mathrm{Ti}$ \\
\hline HCT590X $+\mathrm{Z}$ & Max 0.15 & Max 0.75 & Max 2.5 & Max 0.04 & Max 0.015 & $0.015-1.5$ & Max 1.4 & Max 0.15 \\
\hline
\end{tabular}

\subsection{Hole-forming process}

The hole-forming process is realised in a two stage process. The setup of the hole-forming process and the tools used are shown schematically in Fig. 1. In the first step, the sample is heated above the melting temperature via an infrared (IR) spot (Type 600.5010.1), manufactured by Optron GmbH, Garbsen, Germany whilst avoiding overheating above the degradation temperature of the polymer. The nominal focal spot diameter at the focus distance is specified to $10 \mathrm{~mm}$. The CFRT sample is placed in the positioning tool. Changeable masks allow to define the size irradiated area and consequently the molten area in which fibre rearrangement can take place. The main component of this tool is manufactured from tool steel and has a cavity in the shape of the CFRT sample. Into the cavity a polyetheretherketon (PEEK) insert is placed, which features a hole in the diameter of the forming spike to allow the accommodation of the spike during the hole-forming process. The insert is used to reduce conductive heat loss on the non-irradiated surface of the CFRT sample. After the CFRT sample is sufficiently heated, it is manually positioned under a pneumatic piston, with a piston diameter of $80 \mathrm{~mm}$ resulting in a maximum piston force of about $3.000 \mathrm{~N}$ at an operation pressure of 0.6 MPa. The pneumatic piston is equipped with an adaptor, which allows it to fit changeable spike tools featuring a cylindrical reconsolidation zone with a diameter of $20 \mathrm{~mm}$ allowing to apply uniform pressure to the CFRT sample during the cooling stage after hole-forming.

After the spike tool penetrates the CFRT sample, it is cooled to room temperature under constant pressure in order to crystallize the matrix and to reconsolidate the composite. Once the sample is cooled, the spike tool is extracted leaving a formed hole. A pronounced ridge which accommodates the displaced material as described in [18] could not be detected in pre trials. This can be explained by the comparably low displaced volume as well as a certain amount of air pockets in the CFRT material which lead to a degree of "compressibility" which can accommodate displaced material.

In order to guarantee a sufficient warming above the melting of the matrix and to avoid premature crystallisation whilst preventing overheating, preliminary tests are conducted with the same procedure as described in [13], but with material with reduced thickness. This procedure is carried out for all investigated mask diameters, which leads to unique sets of parameters with regard to IR-power setting and heating time.

\subsection{Calculation of fibre displacement and required molten zone}

The hole-forming process creates a fibre displacement around the formed hole as the spike tool pierces through the laminate which leads to an elongation of the displaced fibres. This fibre elongation is dependent of geometric criteria, mostly the hole diameter and the size of the

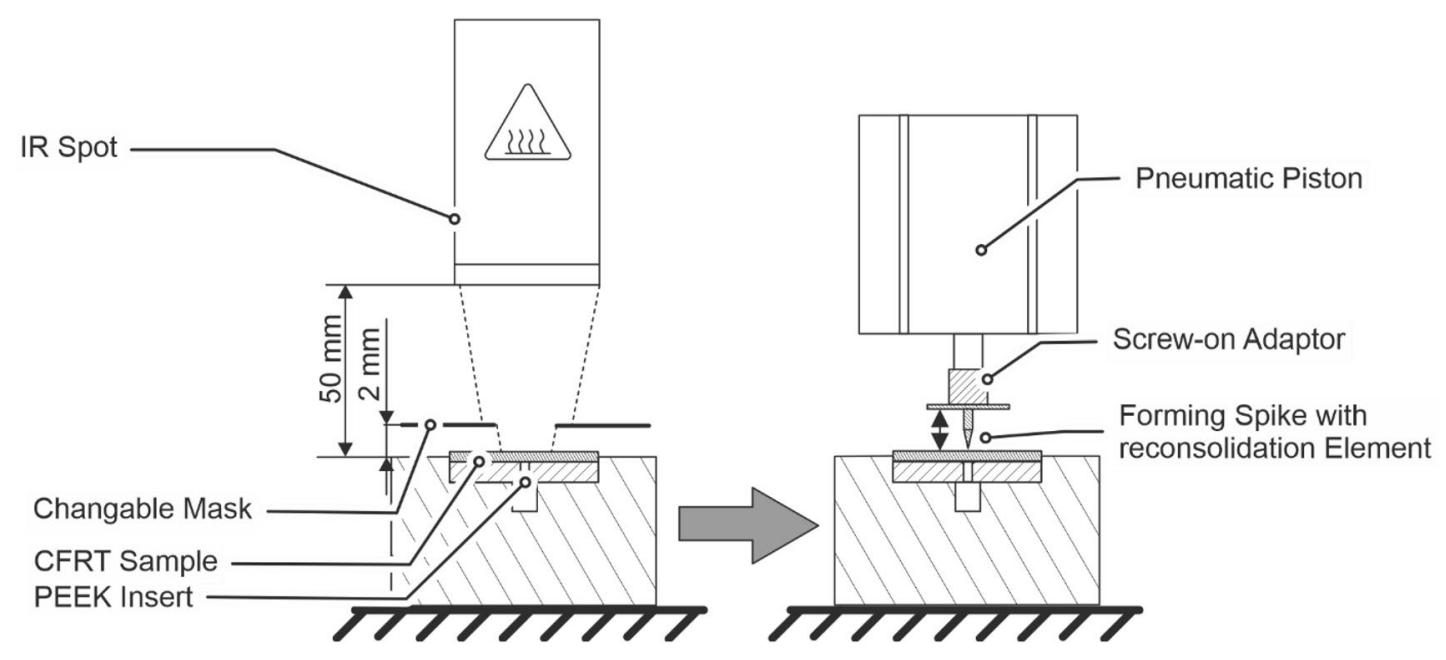

Fig. 1 Schematic illustration of the heating and hole-forming device 
molten zone in which fibres can be displaced. The resulting fibre elongation increases with larger pin diameter and decreases with a larger molten zone. It is crucial that the elongation caused by the hole-forming process is below the sum of the fibre elongation at break and the elongation reserve due to fibre undulation in order to avoid fibre breakage, which would weaken the joints. Non-crimp fabrics, as used in this study, usually have a low elongation reserve due to low fibre undulation when compared to woven fabrics. Mattner et al. [14] exemplarily measured the fibre elongation reserve on a unidirectional reinforced CFRT sample of the type KP-PP09 BK (Kingfa SCI. \& Tech. Europe). It was found that $50 \%$ of the fibres have an elongation reserve of less than $0.162 \%$ and $95 \%$ have an elongation reserve of less than $0.364 \%$. Since these values are comparably low and due to statistical distribution, some fibres must be expected to be completely aligned in the initial state, the elongation reserve is neglected in the following calculations and only the elongation at break is used to calculate the maximum fibre displacement 14 . The fibre elongation $\varepsilon_{F}$ can be calculated with the following equation [9]:

$\varepsilon_{F}=\frac{2 * c-l_{0}}{l_{0}}$

With $l_{0}$ being the fibre length in the initial state and $c$ being the half fibre length after hole-forming. Under the precondition that the diameter of the molten zone $D$ is significantly larger than the pin diameter $d$, the resulting fibre elongation can be approximated with the following equation (compare Fig. 2) [9]:

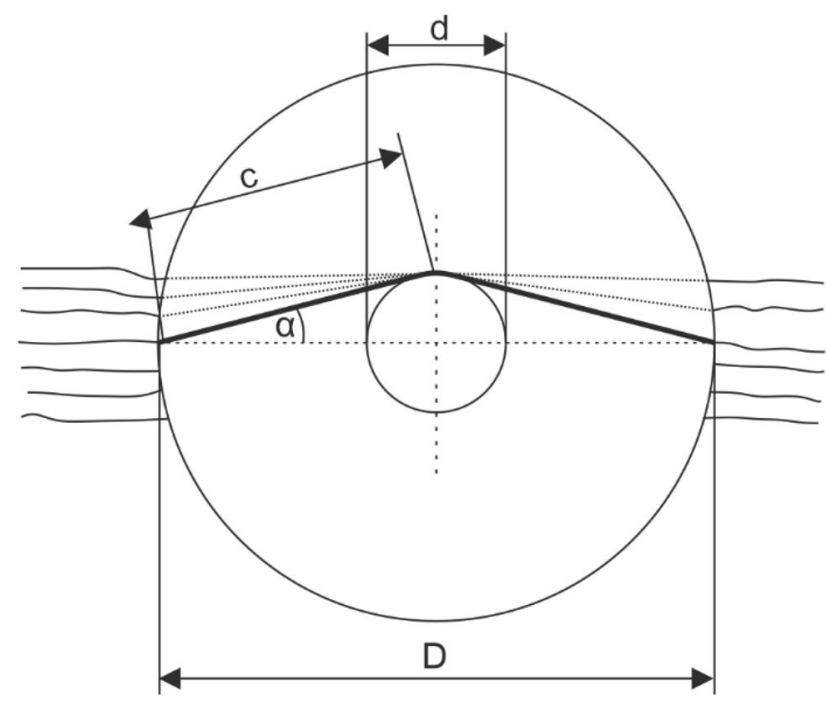

Fig. 2 Fibre displacement of the hole-forming process according to [9]
$\varepsilon_{F}=\frac{1}{\cos \left(\arctan \left(\frac{d}{2 * l_{0}}\right)\right)}-1$

As the initial fibre length and the diameter of the molten zone are identical, it is possible to calculate the required diameter of the molten zone $D_{\text {req. }}$ in dependence of the hole diameter $d$, and the elongation at break $\varepsilon_{\text {max }}$ :

$D_{\text {req. }}=\frac{d}{\sqrt{\varepsilon_{\text {max }} *\left(2+\varepsilon_{\text {max }}\right)}}$

A hole diameter of $1.50 \mathrm{~mm}$ is investigated in this study. In the literature, values of the elongation at break for E-Glass fibres are typically around $4.8 \%$ [15]. It has to be noted that if the fibres are elongated to their elongation at break, the fibres are at their maximum tension and consequently cannot transmit any further loads when being joined. In order to have a safety factor of $25 \%$, the maximum elongation used to calculate the required molten zones is $3.6 \%$, which leads to the required molten zones shown in Table 2 .

In order to validate these calculations and to study the effects of different fibre elongations during hole-forming, three masks with different opening diameters are manufactured $(2.5 \mathrm{~mm}, 4.0 \mathrm{~mm}$ and $5.5 \mathrm{~mm})$. Previous investigations with a mask of a diameter of $7 \mathrm{~mm}$ showed that the resulting molten zone is approximately $40 \%$ larger than the mask diameter [13] which results in expected dimensions of the molten zone and expected fibre elongations as shown in Table 3.

\subsection{Imaging analysis}

In order to measure the actual dimension of the molten zone and of the fibre orientation, transmitted microscopic images are created of samples after the heating phase and after the hole-forming processes using a Discovery V12 (Carl Zeiss Microscopy GmbH, Jena, Germany). For each mask diameter, five samples are measured and the average dimension of
Table 2 Required molten zones in dependency of the hole diameter with an assumed elongation at break of $4.8 \%$ and $3.6 \%$

\begin{tabular}{ll}
\hline $\mathrm{d}$ & $1.50 \mathrm{~mm}$ \\
$\mathrm{D}_{\text {req. }}\left(\varepsilon_{\text {max }}=4.8 \%\right)$ & $4.80 \mathrm{~mm}$ \\
$\mathrm{D}_{\text {req. }}\left(\varepsilon_{\text {max }}=3.6 \%\right)$ & $5.54 \mathrm{~mm}$ \\
\hline
\end{tabular}

Table 3 Used mask diameters and expected dimensions of molten zones and resulting expected fibre elongation

\begin{tabular}{llll}
\hline $\mathrm{D}_{\text {mask }}$ & $2.50 \mathrm{~mm}$ & $4.00 \mathrm{~mm}$ & $5.50 \mathrm{~mm}$ \\
$\mathrm{D}_{\text {expected }}$ & $3.50 \mathrm{~mm}$ & $5.60 \mathrm{~mm}$ & $7.70 \mathrm{~mm}$ \\
$\varepsilon_{\text {expected }}$ & $7.7 \%$ & $3.6 \%$ & $1.9 \%$ \\
\hline
\end{tabular}


the molten zone is calculated in $0^{\circ}$ and $90^{\circ}$ to the main fibre direction. Furthermore, micro sections of joined samples perpendicular to the fibre orientation are created to assess the geometry of the caulked pin and to review if damages in the CFRT component can be detected.

For the micro-computer-tomography $(\mu \mathrm{CT})$ analysis, a computer-tomograph of the type sub $\mu$-CT (Fraunhofer Institute for Integrated Circuits (IIS) e.V., Erlangen, Germany) is used. The samples are cut to a dimension of approximately $20 \mathrm{~mm} \times 20 \mathrm{~mm}$ in order to allow a sufficient magnification with a water-cooled saw. The scans are sighted in detail, following the path of individual fibres and analysing them for the fibre rearrangement as well as potential fibre breakage, indicated by sudden shifts in direction, internal open ends or sudden voids. One sample of each defined mask diameter is investigated.

\subsection{Cold extrusion of pin structures}

The metallic pin structures are formed by cold extrusion from the sheet metal plane. For this purpose, a multi-acting tool was used that allows the blank holder and the forming punch, which performs the forming work, to be controlled independently of each other. The process sequence is shown schematically in Fig. 3. The process starts with the application of the blank holder pressure $\sigma_{B H}$ of $250 \mathrm{MPa}$ to prevent bulging of the sheet and to limit radial material flow that occurs during extrusion of the pin structure. After the pressure is applied, the forming punch with a diameter $d_{P}$ of $3 \mathrm{~mm}$ moves axially downwards at a constant speed $v_{P}$ of $5 \mathrm{~mm} / \mathrm{min}$ and penetrates the DP600 sheet. This displaces the material located directly above the cylindrical die cavity with a diameter $d_{D}$ of $1.5 \mathrm{~mm}$ mainly axially downwards into the cavity. The material below the punch, which is not directly above the cavity, is partly displaced laterally outwards into the sheet plane and laterally into the die. Mechanical stops are used to limit the punch penetration depth $s$ and thus end the process. The pin height $h$ is controlled by the punch penetration depth. To investigate the caulking process with the material combination of DP600/CFRT, which is explained in more detail below, pin structures with a height of $1.90 \mathrm{~mm}$ were produced using tensile shear specimens as well as cross tension specimens. The used punch penetration depth $s$ used to achieve these pin heights $h$ are listed in Table 4.

\subsection{Definition of advantageous pin geometry for caulking}

In order to define the two suitable levels of upsetting for the pin structures with an initial height of $1.90 \mathrm{~mm}$, which are to be used in the next step for the joining with the perforated CFRT samples, one pin structure was incrementally upset in five steps by $0.2 \mathrm{~mm}$ displacement for each step. The complete pin geometry of the different stages was subsequently measured using an InfiniteFocus G5 optical 3D surface measuring device from Alicona Imaging $\mathrm{GmbH}$, Raaba, Austria. In this way, the profiles of the individual stages could be investigated and suitable stages were identified for joining steel pin and CFRT specimen via caulking. Therefore, the diameters of the upset pins of the individual stages were measured at the pin head, pin-base and at a pin height of $1 \mathrm{~mm}$, as the CFRT samples have a thickness of $1 \mathrm{~mm}$. The evolution of the upsetting of the pin structure is depicted in Fig. 4. Since the cold extrusion process causes a punch indentation on the back of the sheet on which the pin structure is located, this cavity is filled with sheet metal discs (see Fig. 5), which are laser cut to the diameter of the

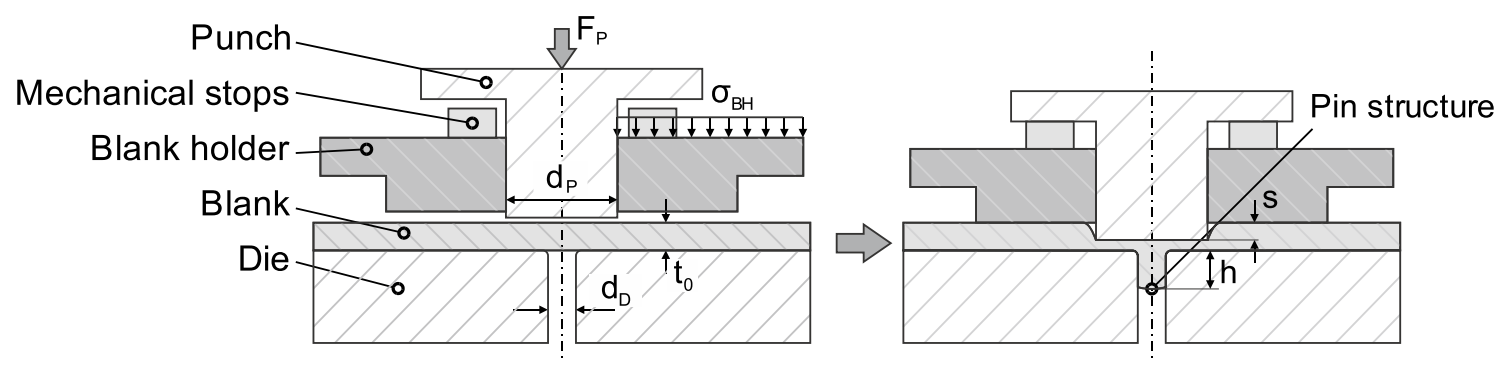

Fig. 3 Schematic illustration of the cold extrusion process of the pin structures

Table 4 Used Pin penetration depth $\mathrm{s}$ and corresponding pin height $\mathrm{h}$ during pin extrusion depending on the sample type

\begin{tabular}{llllr}
\hline Material & Specimen types & $\begin{array}{l}\text { Punch penetration } \\
\text { depth s }[\mathrm{mm}]\end{array}$ & Pin height $\mathrm{h}[\mathrm{mm}]$ & $\mathrm{n}$ \\
\hline DP600 & Tensile shear specimen & $0.89 \pm 0.00$ & $1.90 \pm 0.02$ & 14 \\
& Cross tension specimen & $0.84 \pm 0.00$ & $1.90 \pm 0.01$ & 10 \\
\hline
\end{tabular}




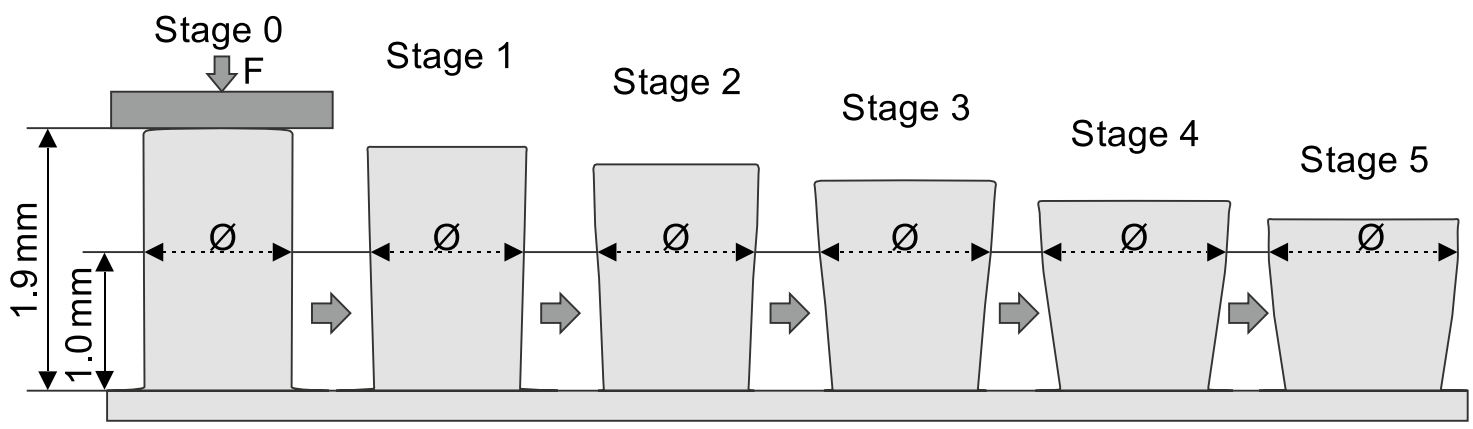

Fig. 4 Illustration of the incremental upsetting of the pin structure with its different upsetting stages and the diameter at a height of $1 \mathrm{~mm}$

Fig. 5 Schematic illustration of the caulking process

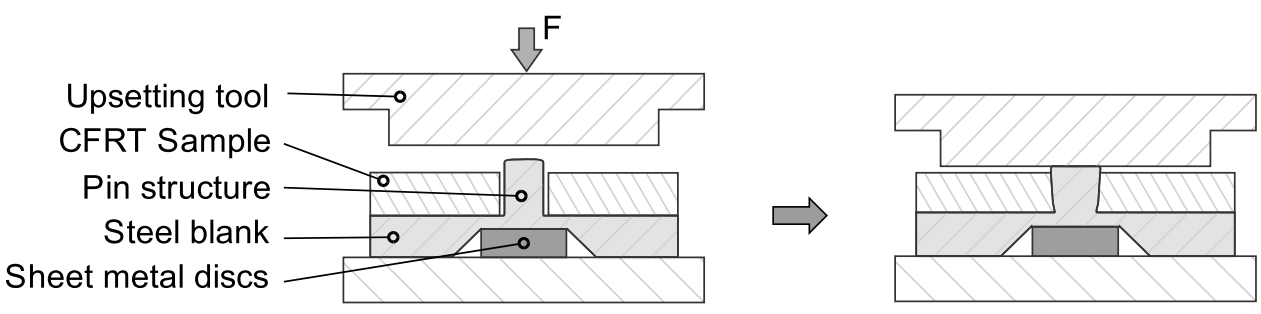

punch to fit into the punch indentation and have a height of the punch penetration depth. These discs prevent the pin structure from bending back into the punch indentation or being damaged during the joining process. Subsequently, the pin structure is placed between two conventional upsetting tools in a universal testing machine. At the beginning of the caulking process, the upper upsetting tool moves axially downwards until it comes into contact with the pin structure and a pre-force of $20 \mathrm{~N}$ has been reached. The process then continues as the upsetting tool moves downwards at a constant speed of $1 \mathrm{~mm} / \mathrm{min}$ and compresses the pin structure by a set displacement value.

\subsection{Caulking process}

The joining strategy, which is investigated in more detail in this work, in order to join steel and glass fibre-reinforced polypropylene with the help of pin structures produced by cold forming, is caulking. This joining process is schematically illustrated in Fig. 5. Here, the cold-extruded pin structure is first inserted through the CFRT sample in such way, that the side of the CFRT component, where the forming spike exited the sample, faces the steel specimen. Because of this, the funnel shaped fibre morphology caused at the entry side by the hole-forming process can better accommodate the conical pin head after the caulking process. In the following step, the two joining partners are placed between two conventional upsetting tools in a Zwick\&Roell Z 10 universal testing machine. The caulking process of the pin structure itself was conducted in the same way as the incremental upsetting process with respect to the process parameters and the preparation of the punch indentation. Two different upsetting levels were used to investigate the influence on the joint strength in both the tensile shear test and cross tension test and to analyse possible matrix damage caused by the joining process and the increase in pin diameter.

\subsection{Mechanical characterisation}

In the scope of the mechanical characterisation, three different investigation methods are conducted. First, the ultimate bearing load and the bearing strength of formed holes in the CFRT samples before the joining process is measured with a test arrangement based on Hufenbach et al. [8] and a testing speed of $10 \mathrm{~mm} / \mathrm{min}$. The results of this test function as a baseline of the maximum achievable strength of the joint and are supposed to help identifying damages caused by the caulking process, which would become visible as reduced strength of caulked hybrid CFRT/steel samples in comparison to the bearing strength. This test is conducted with a universal testing machine type Zwick\&Roell Z10.

The mechanical characterisation of the joined specimens is based on the technical bulletin DVS 3480-1 [16]. The cross tension tests as well as tensile shear tests are performed with a testing speed of $10 \mathrm{~mm} / \mathrm{min}$. For the tensile shear tests, a universal testing machine type Zwick\&Roell Z1465 is used with a sample size of three in $0^{\circ}$ and $90^{\circ}$ of the fibre orientation and for the cross tension tests (mode 1), a universal testing machine type Zwick\&Roell Z10 is utilized with a sample size of five. Before the tests, the samples are stored in normalized climate at $23{ }^{\circ} \mathrm{C}$ and $50 \%$ rel. humidity. The larger sample size for cross tensile tests can be explained 
Fig. 6 Exemplary cross tension (left) and tensile shear (right) samples

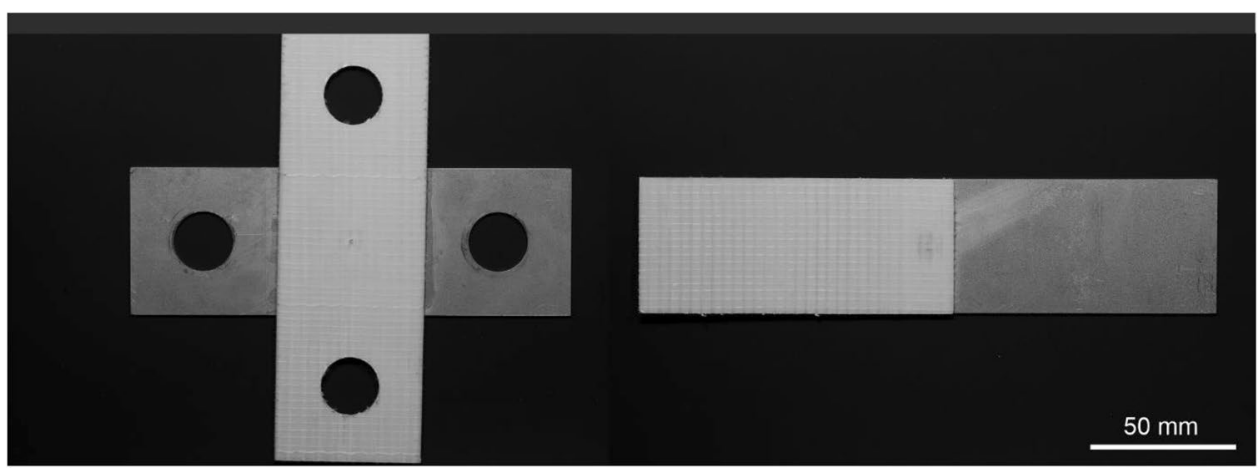

Table 5 Defined heating parameters for hole-forming experiments

\begin{tabular}{llll}
\hline $\mathrm{D}_{\text {mask }}$ & $2.5 \mathrm{~mm}$ & $4.0 \mathrm{~mm}$ & $5.5 \mathrm{~mm}$ \\
Power & $\mathrm{n} / \mathrm{a}$ & $90 \mathrm{~W}$ & $56 \mathrm{~W}$ \\
HeatingTime & $\mathrm{n} / \mathrm{a}$ & $240 \mathrm{~s}$ & $240 \mathrm{~s}$ \\
\hline
\end{tabular}

with a higher scatter shown in pre-trials in this load direction and a limited number of available CFRT shear specimen with formed holes with both fibre orientations. Figure 6 shows exemplary cross tension and tensile shear samples with the same dimensions as used in the present study.

\section{Results}

\subsection{Hole morphology and fibre orientation}

It showed that with a mask diameter of $2.5 \mathrm{~mm}$ a complete heating above the melt temperature was not possible even with a power setting of $100 \%$, as not enough radiative energy could be transmitted through the mask opening to balance the heat loss due to conduction, convection and radiation and the temperature stagnated at a level below the melt temperature of the polymer. The chosen parameter settings for the mask of $4.0 \mathrm{~mm}$ and $5.5 \mathrm{~mm}$ are displayed in Table 5 .

The investigation of the transmitted light microscopy image shows that the measured size of the molten zone is larger in the main orientation of the fibres $\left(0^{\circ}\right)$ than perpendicular to the fibre orientation $\left(90^{\circ}\right)$. This can be explained with a higher thermal conductivity along the fibre direction. In comparison to the expected dimensions of the molten zones, the measurements reveal significantly larger dimensions, while the difference between a mask of $4.00 \mathrm{~mm}$ and $5.50 \mathrm{~mm}$ in diameter is relatively small. With a mask of $4.00 \mathrm{~mm}$, a diameter of $10.45 \mathrm{~mm} \pm 0.27 \mathrm{~mm}$ in $0^{\circ}$ and of $9.75 \mathrm{~mm} \pm 0.38 \mathrm{~mm}$ in $90^{\circ}$ is measured. With a $5.50 \mathrm{~mm}$ mask a diameter of $10.83 \mathrm{~mm} \pm 0.66 \mathrm{~mm}$ in $0^{\circ}$ and of $9.55 \mathrm{~mm} \pm 0.46 \mathrm{~mm}$ in $90^{\circ}$ is measured. This finding does not correspond with the assumption that the actual molten

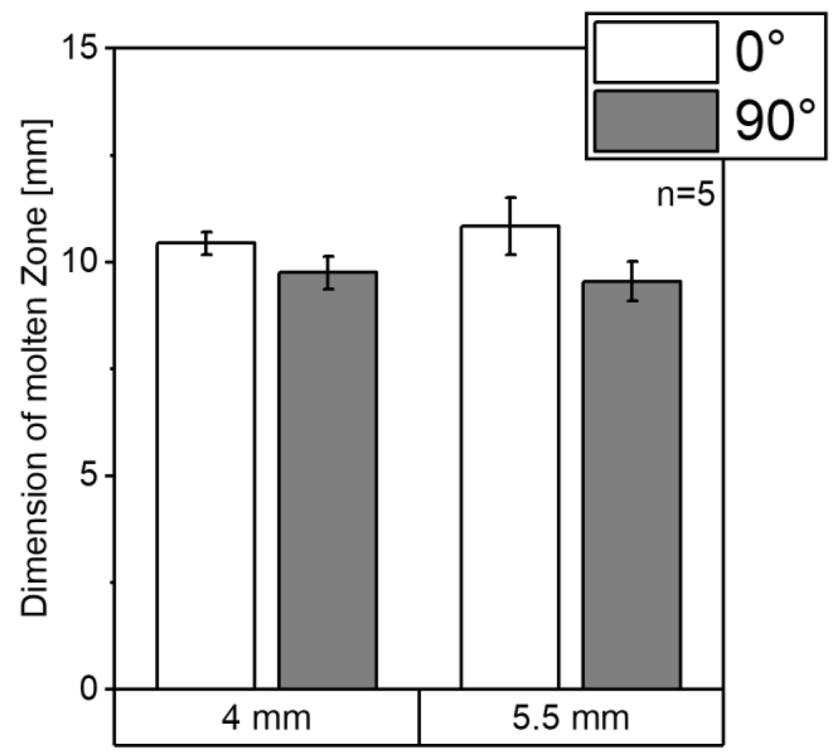

Fig. 7 Measured molten Zone in $0^{\circ}$ and $90^{\circ}$ of the main fibre orientation

zone is $40 \%$ larger than the irradiated area. It appears that below a certain mask diameter, the resulting molten zone cannot be further reduced in size due to thermal conduction effects influencing the thermal equilibrium. This is a topic that requires further investigations in the future. Figure 7 summarizes the results. As a consequence, a mask diameter of $5.5 \mathrm{~mm}$ is chosen for the joining experiments, as the dimensions of the molten zones are practically identical but the IR-power setting with a larger mask is lower which is leading to reduced thermal exposure of the CFRT surface.

When investigating the resulting fibre morphology of the formed holes, a similar fibre displacement can be seen, which is basically independent of the mask diameter. Figure 8 shows exemplary images in three different planes of a perforated sample, which was heated with a $5.5 \mathrm{~mm}$ mask. In the $x / y$ plane, it can be seen that the fibre roving is split as it is expected in the calculation of the fibre displacement (compare Fig. 2). Distinct fibre-free zones can be seen over 


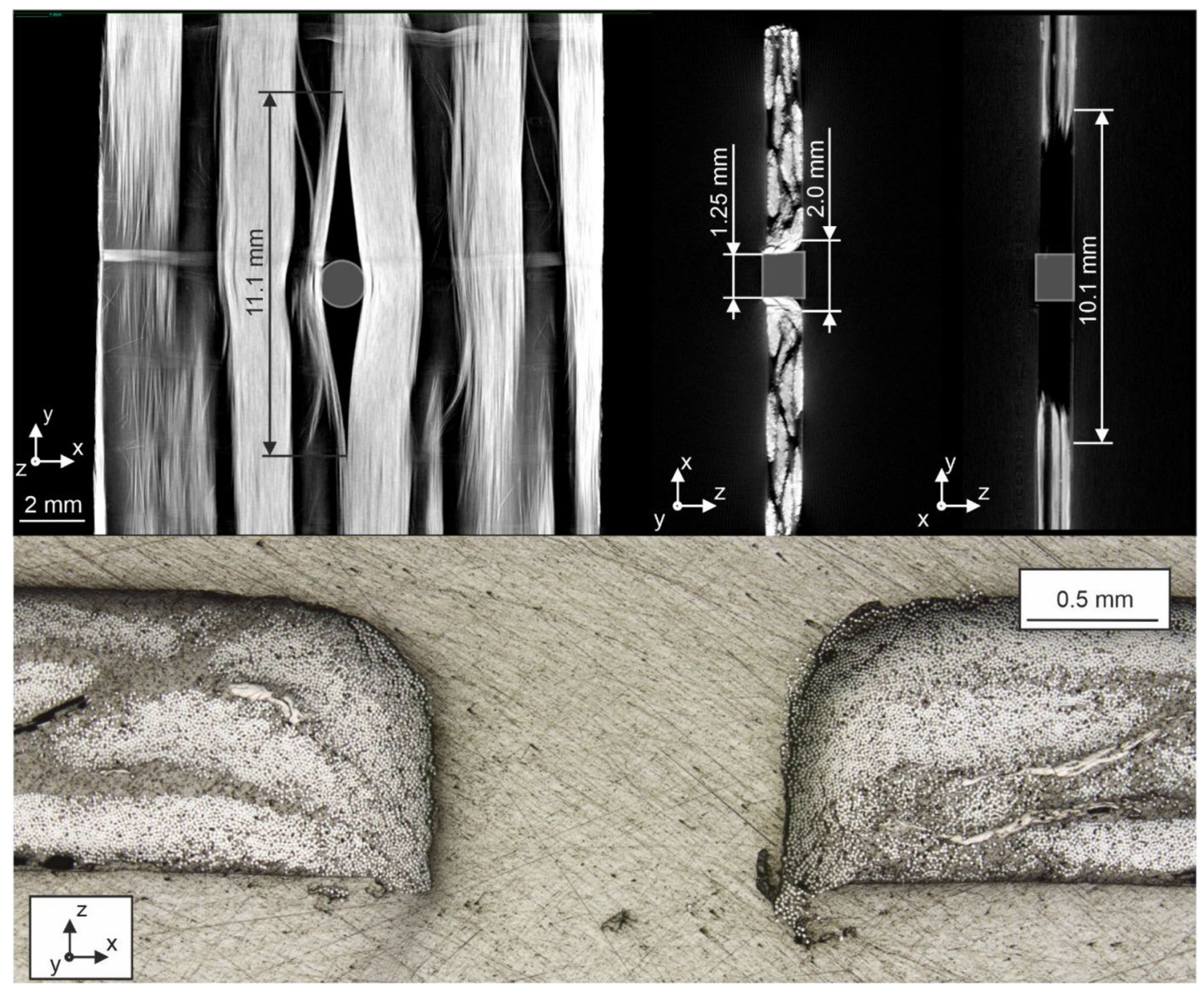

Fig. 8 CT images in three planes of one exemplary sample (top, formed holes are illustrated as grey circle and rectangular) and micro section of a second sample (bottom). Holes formed with $1.5 \mathrm{~mm}$ spike, reconsolidation force: $2.500 \mathrm{~N}$, piston speed: $0.11 \mathrm{~mm} / \mathrm{s}$

and below the formed hole. The length of the fibre-free zones is measured to $11.10 \mathrm{~mm}$, which corresponds well with the measured size of the molten zone of $10.83 \mathrm{~mm}$ with a $5.5 \mathrm{~mm}$ mask.

In the $\mathrm{x} / \mathrm{z}$ plane, the formed hole is clearly visible, the penetration of the sample was performed from the right side to the left side. A characteristic funnel-shaped fibre morphology can be observed with fibres being dragged in the direction of the penetration. A similar behavior can be observed for the thermoactivated pinning process, which is described in [17]. Consequently, the fibre-free zone on the right side, which is $2.0 \mathrm{~mm}$, is larger when compared with the left side, which is only measured to $1.25 \mathrm{~mm}$. It has to be noted that areas without fibres do not necessarily indicate voids or the exact dimension of the formed hole, since the matrix material cannot be seen in the CT images. The deviation of the measured value of the hole dimension from the CT image of $1.25 \mathrm{~mm}$ and the diameter of the forming spike of $1.50 \mathrm{~mm}$ can be explained with two phenomena: First it is possible that the CT image does not precisely display the middle plane of the formed hole leading to reduced measured diameter. Second, internal stresses in the fibres can lead to a shrinkage of the formed hole perpendicular to the fibre direction as already described in [18]. In the $y / z$ plane, the fibre-free zone can be clearly seen. It is noticeable that the measured dimension of the fibre-free zone is shorter than in the $x / y$ plane. An explanation for this phenomena can be that the image in the $y / z$ plane is not precisely aligned with the fibre-free zone. Due to the steep angle of the fibre-free wedges, a small offset can already lead to a significant deviation in the measurements.

Based on the measured average dimension of the molten zone with a $5.50 \mathrm{~mm}$ mask of $10.83 \mathrm{~mm}$, the average fibre elongation for joined samples can be calculated to $1.11 \%$ using Eq. 2. This is significantly lower than planned in the experimental setup but is expected to be beneficial to the joint strength, as the fibres are exposed to less preelongation caused by the joining process. 
a

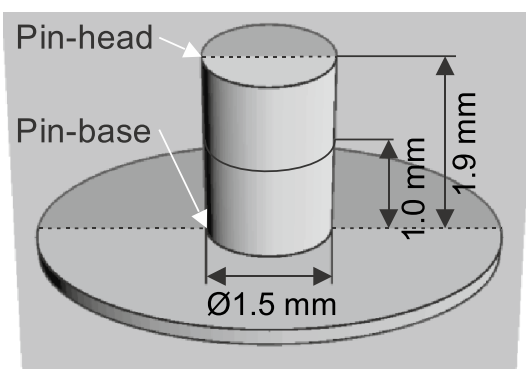

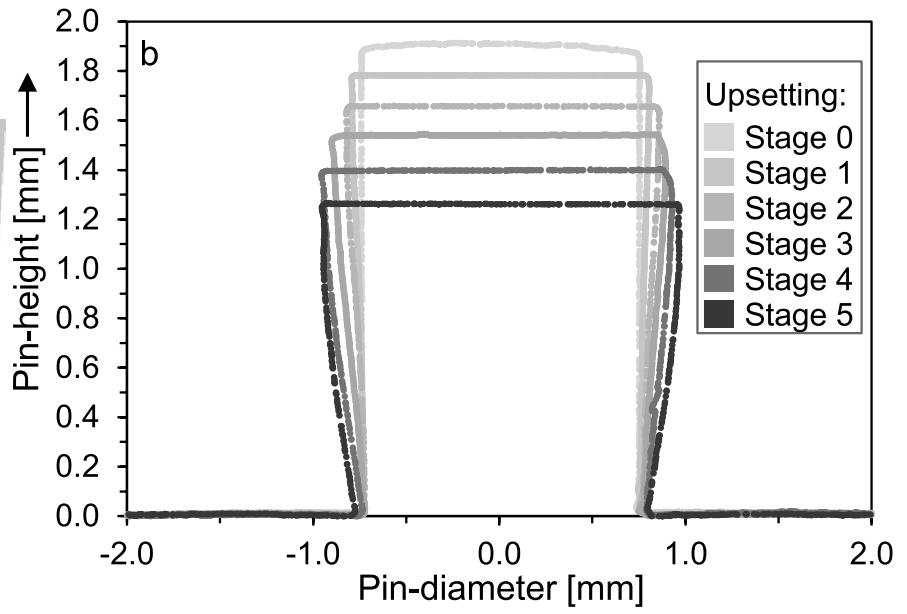

c

Fig. 9 a Schematic representation of the position of the profile section using the initial pin (stage 0) as an example, $\mathbf{b}$ profiles of the upsetting stages investigated, $\mathbf{c}$ results of the geometric characteristics

\subsection{Incremental pin upsetting}

Figure 9 shows the results of the incremental pin upsetting. Figure 9a shows the position of the section plane for the measurement of the profiles from Fig. $9 \mathrm{~b}$ as well as the position of the measured diameters using stage 0 as an example. Figure $9 \mathrm{c}$ then summarises the determined values for the pin height, the measured diameters and percentage of pin upsetting. When investigating the profiles shown in Fig. 9b, the constant axial compression of the pin structure can be seen, which leads to a continuous broadening of the pin head. Thus, the height of the pin structure reduces from an initial height of $1.90 \mathrm{~mm}$ at stage 0 by $33.77 \%$ to a height of $1.26 \mathrm{~mm}$ at stage 5 . However, the head diameter increases from the initial diameter of $1.49 \mathrm{~mm}$ by $32.22 \%$ to $1.97 \mathrm{~mm}$, which results from the radial material flow due to the axial compression. By analysing the shape of the pin structures more closely, however, the rather conical shape of the pin structure is noticeable. In conventional upsetting, the friction between the component and the upsetting tool tends to cause the component to bulge. In the current case, however, the pin structure is fixed to the sheet metal at the pinbase, which limits relative movement in the radial direction. of the pin structure measured using an optical 3D profilometer (Alicona InfiniteFocus G5) at different upsetting stages. *Upsetting of the pin structure compared to stage 0 in percent

Furthermore, the strain hardening of the material during pin extrusion provides another explanation for the main broadening of the pin structure at the pin head. Here, in particular, the strength increases in the edge area of the pin shell, due to the flow of the material over the shoulder into the die cavity, and also in the pin-base, due to the increasing compression of the material by the axial punch penetration depth. This strain hardening, especially in the pin-base, increases further with greater punch penetration depth. In contrast, the material in the middle of the pin head area, which is mainly axially displaced at the beginning of the forming process, experiences less plastic deformation and thus work hardening, which is why the start of material flow is at a lower stress level here than in the pin-base. For this reason, there initially is a greater increase in diameter in the head area of the pin structure, as the material begins to flow earlier. With further upsetting of the pin structure, the diameter at a height of $1 \mathrm{~mm}$ from the pin-base converges to the head diameter due to the decrease in height (see Fig. 9c). Since two different compression stages were investigated in the context of the work with regard to their effects on the joint characteristics, stage 2 and stage 4 were used for the further experimental investigations. In this way, a variation in the 
pin height as well as the pin geometry is ensured. Furthermore, a filling of the geometry created by the hole-forming of the CFRT sample (compare Fig. 8) should be achieved with the stronger compression, in order to fill the undercut as much as possible with matrix and especially with fibres.

\subsection{Caulking process}

The graph in Fig. 10 shows the force-displacement curve for two pin structures during upsetting using the two different upsetting stages. The behaviour is very similar regardless of the type of specimen used, which is why the behaviour is explained using the example of the results for the tensile shear specimen. The process starts with a small amount of play until the sample rests flat due to the slight pretension caused by the pin extrusion and then changes to the elastic component of the curve, when the pin structure is elastically deformed. As the process progresses, the elastic-plastic deformation follows, in which the pin structure is compressed, as described before and the axially displaced material flows radially outwards, which initially leads to an increase in diameter, particularly at the pin head, and results in a conical pin geometry. The force-displacement curves of the two upsetting stages differ only in the maximum force and maximum displacement and are otherwise, as expected, superimposed. Here, a maximum force of $2100 \mathrm{~N}$ is required for forming in stage 2 at a displacement of $0.4 \mathrm{~mm}$ and $2500 \mathrm{~N}$ in stage 4 at a displacement of $0.6 \mathrm{~mm}$.

The optical investigation of the joints with two different caulking degrees shows that a distinct form-fit can be achieved with this process (see Fig. 11). As expected, the form fit is more pronounced with a higher caulking degree. Although the pin diameter is partially larger than the diameter of the forming spike, which consequently causes deformations of the CFRT component, no large damages like deconsolidation or cracks can be seen in the micrographs in Fig. 11, regardless of the caulking degree. Furthermore, a significantly increased fibre content close to the pin structure can be seen in both images. This is caused by the holeforming process, where fibres are displaced by the forming spike, which leads to locally increased fibre contents. This high fibre content is therefore, due to the plastic deformation of the pin structure, located in the undercut of the pin structure. Also, the analysis of the micrographs reveals a stronger

Fig. 10 Force-displacement curves of the two upsetting stages used for joining using the tensile shear specimen as an example
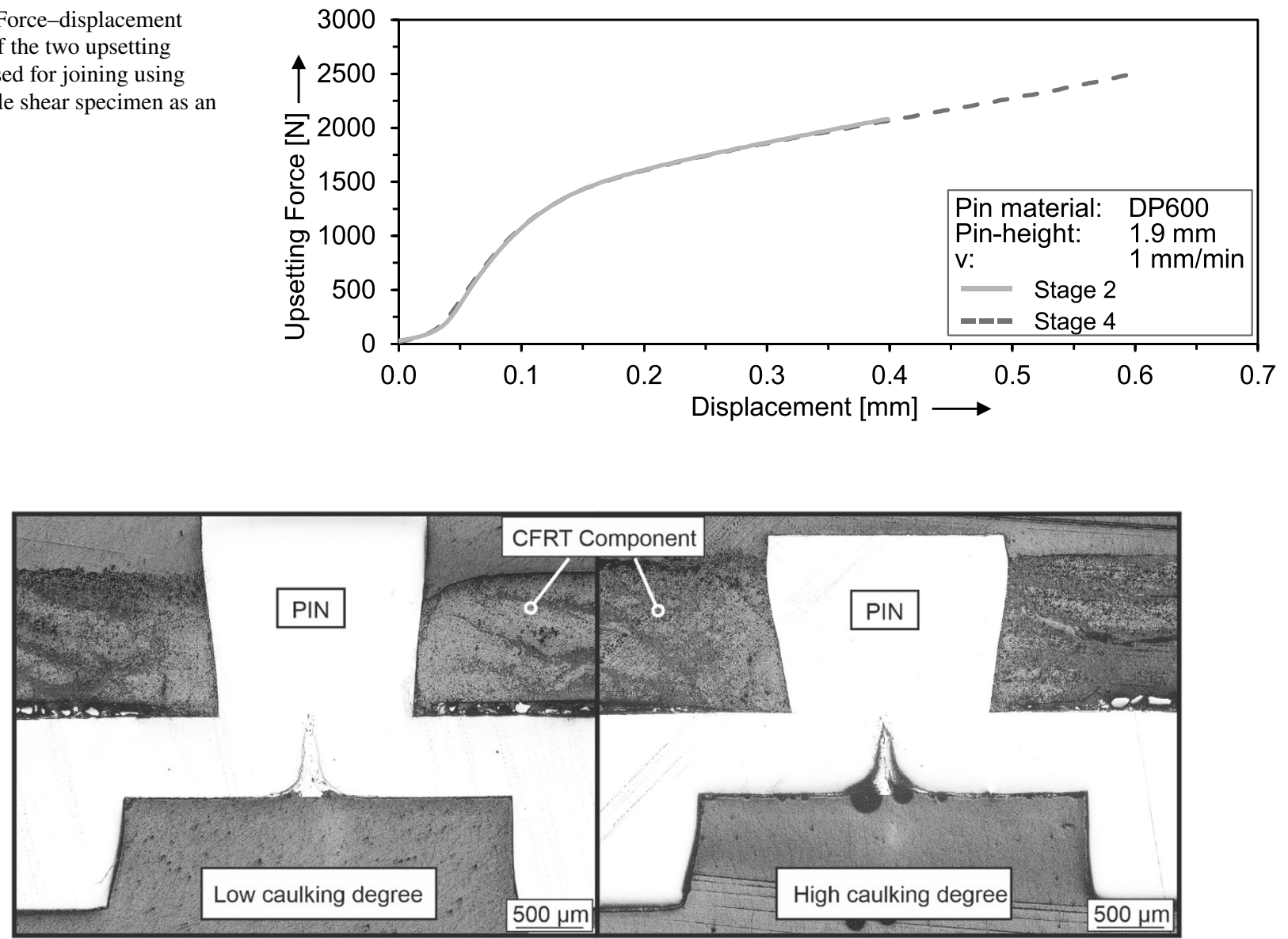

Fig. 11 Comparison of low (stage 2, left) and high caulking degree (stage 4, right). Microscopic image in $90^{\circ}$ to main fibre orientation 
undercut at the higher degree of upsetting. It is assumed that this phenomenon is beneficial for the joint strength and here in particular for the cross tension test, as the resistance to axial pull-out of the pin structure should be improved by the good filling of the undercut with fibres and furthermore by the higher upsetting degree.

\subsection{Mechanical characterisation}

\subsubsection{Ultimate bearing load and bearing strength}

When investigating the ultimate bearing load, it can be seen that with increasing hole diameter the ultimate transmitted force is increasing and that the samples are stronger when loaded in $90^{\circ}$ to the fibre orientation (compare Fig. 12). The highest ultimate load is measured for $1.50 \mathrm{~mm}$ holes with $405.6 \pm 13.3 \mathrm{~N}$ in $90^{\circ}$ and $185 \pm 13.0 \mathrm{~N}$ in $0^{\circ}$. When testing the $1.0 \mathrm{~mm}$ holes, only the experiment in $0^{\circ}$ degree could be tested to $133.6 \pm 6.7 \mathrm{~N}$, as in $90^{\circ}$ the test pin broke during the test. When comparing the ultimate bearing strength, which is calculated as the maximum force divided by the projected area of the formed hole, it shows, that it is almost constant in the range of the standard deviation with a slight tendency for higher values towards smaller hole diameters. The slight increase in bearing strength could be explained by reduced fibre undulation caused with smaller formed holes, which can be expected to increase the strength of the CFRT sample.

\subsubsection{Tensile shear and cross tension strength of the hybrid joints}

Investigating the joined samples, it becomes apparent that under shear load significantly higher forces can be transmitted than under normal load (see Fig. 13). Under normal load, the caulking degree has a relevant influence on the joint strength: with a low caulking degree a maximum force of $48.2 \pm 9.4 \mathrm{~N}$ is reached, while with a high caulking degree a maximum force of $76.2 \pm 6.6 \mathrm{~N}$ can be transmitted corresponding to an increase of $58.1 \%$. As described before, this is due to the greater undercut resulting from the higher degree of upsetting. This results in more matrix and fibres underneath the undercut of the pin structure, which consequently has a higher resistance to the axial force and thus leads to a significantly increased cross tensile strength.
Fig. 12 Ultimate bearing load and bearing strength of formed holes at different diameters and load directions
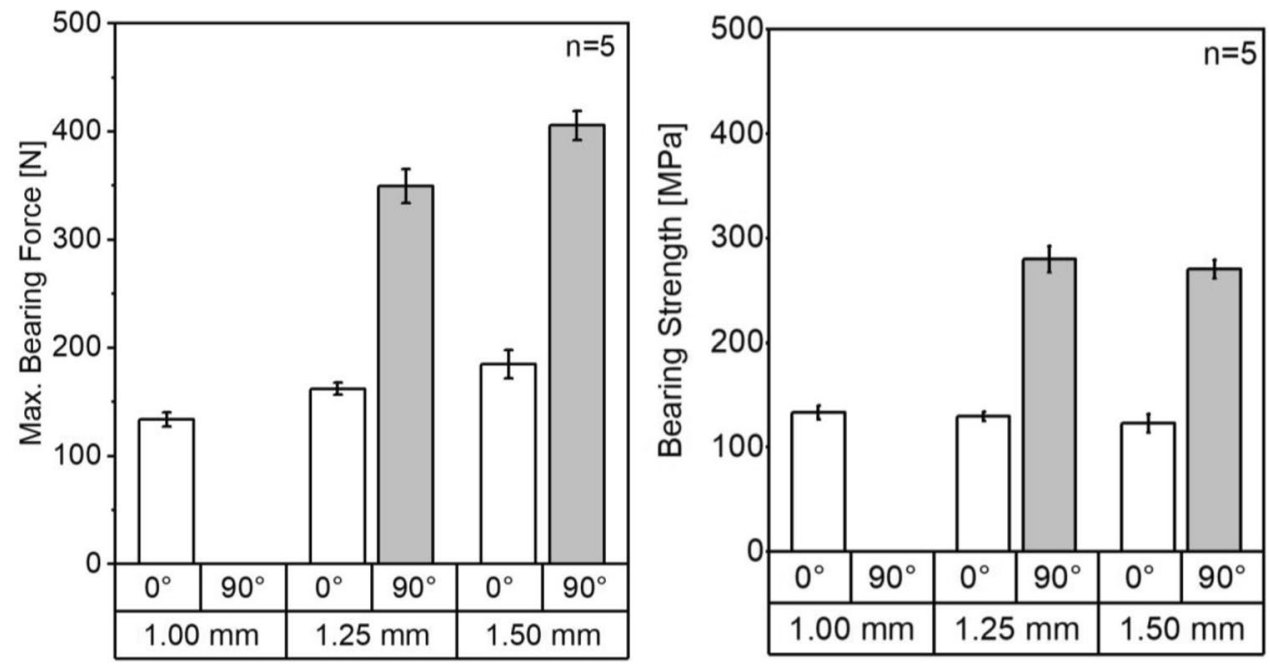

Fig. 13 Shear and head pull load results of joined samples

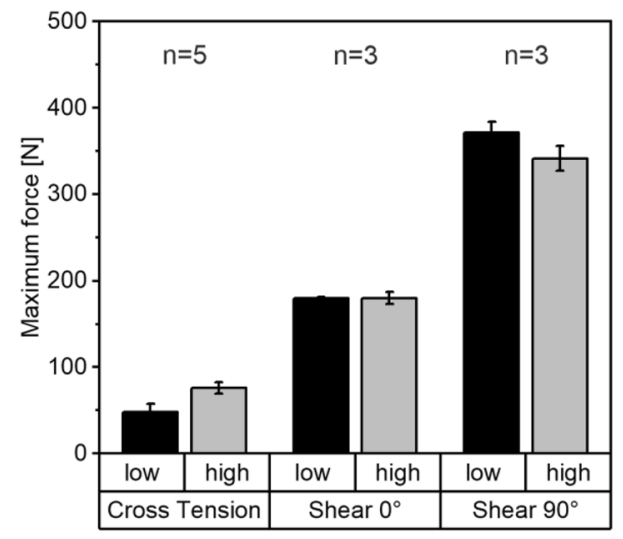


In contrast, under shear load the caulking degree does not have a clear influence on the joint strength: at $0^{\circ}$ $179.7 \pm 1.9 \mathrm{~N}\left(\right.$ low) and $180.0 \pm 7.0 \mathrm{~N}$ (high) and at $90^{\circ}$ $371.3 \pm 12.8 \mathrm{~N}$ (low) and $341.3 \pm 14.5 \mathrm{~N}$ (high) are measured. In fibre direction, the caulking degree has no influence beyond the range of the standard deviation while in $90^{\circ}$ a disadvantage can be seen for a high caulking degree. This could be explained with damages in the CFRT component due to the caulking process. However, the difference is comparably small and the ranges of the standard deviation almost overlap and deviations or inconsistencies in the CFRT component could also be an explanation. Consequently, a final conclusion cannot be drawn at this point and further research is needed. When relating the measured values to the pin foot area, which also refers to the hole diameter of $1.5 \mathrm{~mm}$, the maximum shear strength is $210.1 \pm 7.2 \mathrm{MPa}$ under $90^{\circ}$ to the fibres and with a low caulking degree. The maximum cross tension strength is measured to $43.1 \pm 3.7 \mathrm{MPa}$ with a high caulking degree (see Fig. 13).

When comparing joined samples with the reference of bearing strength experiments with a diameter of $1.5 \mathrm{~mm}$, the transmitted force of the caulked samples is decreased: In $0^{\circ}$ the difference is about $5 \mathrm{~N}$ for both caulking degrees and in $90^{\circ}$ it is between $34.3 \mathrm{~N}$ (low caulking degree) and $64.3 \mathrm{~N}$ (high caulking degree). Possible explanations could again be inhomogeneous CFRT components as well as damages due to the caulking process which would correspond with the findings with reduced shear strength with a higher caulking degree in the previous paragraph.

\subsubsection{Force levels under pin extraction load}

When evaluating the force-displacement curves of each single tested specimen under pin extraction loads, it can be seen that for both caulking degrees, two distinct force levels are present (compare Fig. 14). One explanation for this phenomenon could be found in the meso fibre morphology of the
CFRT samples, being formed with individual rovings, which have locally increased fibre volume content, and relatively matrix rich zones between the individual fibre rovings. This morphology can lead to higher or lower fibre content near the joining zone, while it is expected that a high fibre content directly at the joint is beneficial for the joint strength. This will have to be investigated closer in future studies. Furthermore, it is expected that with multi-pin arrays the shown deviations would be statistically equalized and a reduced standard deviation can be observed.

\section{Conclusion and outlook}

In this work, the hole-forming of glass fibre-reinforced polypropylene was first investigated in order to examine the influence on the fibre rearrangement and the elongation of the fibres in the organo sheet. CFRT-specimens perforated by this process were subsequently joined by caulking with cold extruded pin structures, investigating two different degrees of upsetting, which were previously determined by incremental pin upsetting. In this way, the influence of the degree of upsetting on the tensile shear strength and cross tension strength was analysed. On the basis of the results obtained and presented in this paper, the following conclusions can be drawn:

- The hole-forming process is a viable approach for perforating CFRT specimens prior to pin joining. By concentrating the fibres near the joint hole, a strong joint can be created without inducing fibre damage and thus weakening the material, as it would be for example the case with drilling. This fibre concentration is a particularly important factor for filling the undercut formed during the caulking, which makes hole forming particularly suitable for this process.
Fig. 14 Force-displacement curves of the cross tension tests

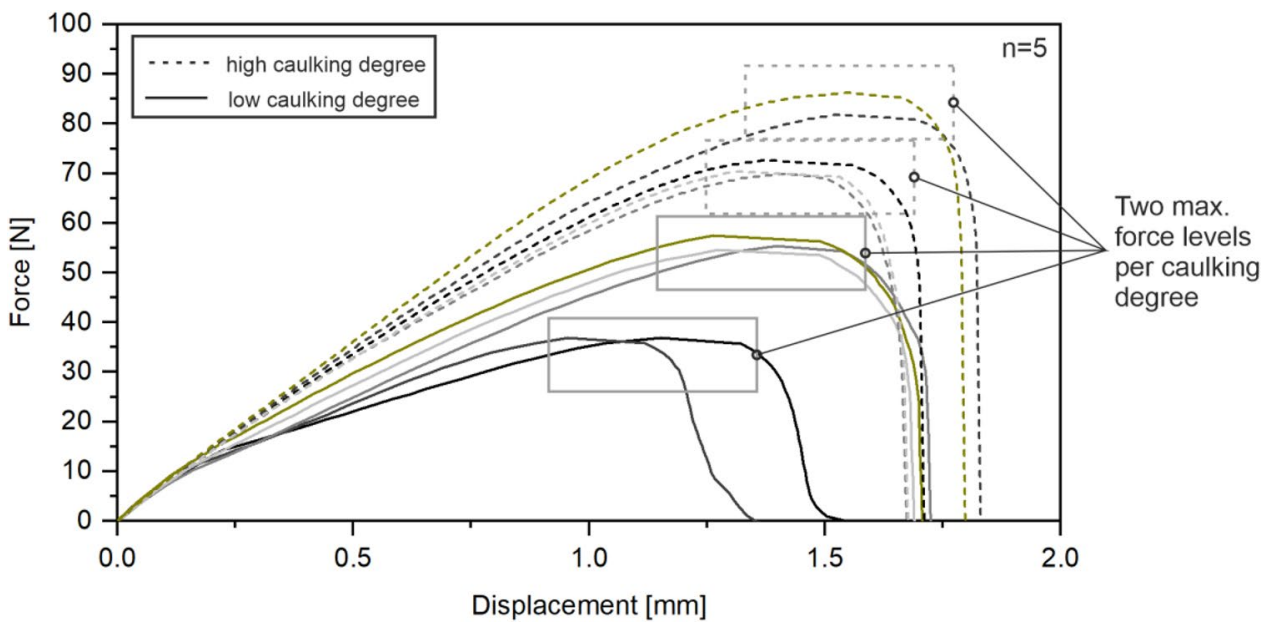


- Varying the pin structures' levels of upsetting enables different cross tension strengths to be achieved with a stronger upsetting level leading to a more pronounced undercut and consequently higher joint strength. Thus, load-adapted joints can be realised.

- Compared to the bearing tests, a reduced strength was found for some tensile shear tests. Based on the fact that there was no failure of the metallic pin structures, the CFRT sample and its properties seem to play a decisive role in the strength of the joint, especially with regard to local fibre concentration in the area of the joint.

- The results show that by using cold extruded pin structures and caulking as a joining method for CFRT-specimen, load-bearing joints can be produced for both tensile shear loads and normal loads without adding weight through auxiliary elements.

Future research should focus, in particular, on investigating the joining characteristics of multi-pin arrays with CFRT specimens. The effect of the pin arrays on the fibre distortion of the CFRT specimen and the resulting effects on the joint strength and possible damage to the fibres are of particular interest. In addition, a more detailed investigation of the influence of the size of the molten zone during the hole-forming process and the resulting pre-elongation of the fibres on the joint strength should be carried out. Furthermore, different fibre architectures and their influence on the hole-forming process should also be investigated in this context. Another interesting aspect would be the investigation of additional levels of upsetting as well as different initial pin heights and their influence on the joint formation, joining partner and joint properties.

Author contributions Conceptualization: DR, JP, DD, MM; Methodology: DR, JP, DD, MM; Formal analysis and investigation: DR, JP; Writing — original draft preparation: DR, JP; Writing — review and editing: DR, JP, DD, MM; Funding acquisition: DD, MM; Resources: DD, MM; Supervision: DD, MM.

All authors contributed to the study conception and design. Julian Popp built the processing equipment including the joining apparatus.

Funding Open Access funding enabled and organized by Projekt DEAL. This work was funded by the Deutsche Forschungsgemeinschaft (DFG, German Research Foundation)-TRR 285 C01-Project-ID 418701707.

Availability of data and material The raw data required to reproduce these findings cannot be shared at this time as the data also forms part of an ongoing study.

Code availability The code required to reproduce these findings cannot be shared at this time as the code also forms part of an ongoing study.

\section{Declarations}

Conflict of interest Not applicable.

Open Access This article is licensed under a Creative Commons Attribution 4.0 International License, which permits use, sharing, adaptation, distribution and reproduction in any medium or format, as long as you give appropriate credit to the original author(s) and the source, provide a link to the Creative Commons licence, and indicate if changes were made. The images or other third party material in this article are included in the article's Creative Commons licence, unless indicated otherwise in a credit line to the material. If material is not included in the article's Creative Commons licence and your intended use is not permitted by statutory regulation or exceeds the permitted use, you will need to obtain permission directly from the copyright holder. To view a copy of this licence, visit http://creativecommons.org/licenses/by/4.0/.

\section{References}

1. Siebenpfeiffer W (2014) Leichtbau-Technologien im Automobilbau, ATZ/MTZ-Fachbuch, 1st edn. Springer-Vieweg, Berlin

2. Thomason JL, Vlug MA (1996) Influence of fibre length and concentration on the properties of glass fibre reinforced polypropylene: 1 tensile and flexural modulus. Compos Part A 27(6):477-484

3. Thomason JL, Vlug MA, Schipper G, Krikor HGLT (1996) Influence of fibre length and concentration on the properties of glass fibre-reinforced polypropylene: part 3 strength and strain at failure. Compos Part A 27(11):1075-1084

4. Thomason JL, Vlug MA (1997) Influence of fibre length and concentration on the properties of glass fibre reinforced polypropylene: 4 impact properties. Compos Part A 28(3):277-288

5. Sommer M, Edelmann K, Wöginger A, Christmann M, Mack J, Medina L (2014) Thermoplastische Prepregs und Halbzeuge. In: Neitzel M, Mitschang P, Breuer U (eds) Handbuch Verbundwerkstoffe. Carl Hanser Verlag, Munich, pp 147-199

6. Mitschang P, Velthuis R, Rudolf R (2014) Fügeverfahren für FKV. In: Neitzel M, Mitschang P (eds) Handbuch Verbundwerkstoffe, 2nd edn. Carl Hanser, München, pp 469-482

7. Dawai Z, Qi Z, Xiaoguang F, Shengdung Z (2018) Review on joining process of carbon fibre reinforced polymer and metal: methods and joining process. Rare Met Eng 47(12):3686-3695

8. Hufenbach W, Gottwald R, Kupfer R (2011) Bolted Joints with moulded holes for textile thermoplastic composites. In: 18th Conference on Composite Materials

9. Leiser J (2006) Beitrag zu innovativen Verbindungstechniken für Hochleistungsverbundwerkstoffe, $\mathrm{PhD}$. Thesis

10. Plettke R, Schaub A, Gröschel C, Scheitler C, Vetter M, Hentschel O, Ranft F, Merklein M, Schmidt M, Drummer D (2014) A new process chain for joining sheet metal to fibre composite sheets. Key Eng Mater 611-612:1468-1475

11. Kraus M, Frey P, Kleffel T, Drummer D, Merklein M (2019) Mechanical joining without auxiliary element by cold formed pins for multi-material-systems. AIP Conf Proc 2113:050006

12. Salzgitter Flachstahl GmbH (2017) Data sheet-HCT590X+Z (HCT600XD / HC340XD*/CR330Y590T-DP**) Mehrphasenstähle zum Kaltumformen-Dualphasenstähle. https://www.salzg itter-flachstahl.de/fileadmin/footage/MEDIA/gesellschaften/szfg/ informationsmaterial/produktinformationen/feuerverzinkte_produ kte/deu/hct590x.pdf. Accessed 21 Dec 2021

13. Popp J, Römisch D, Kleffel T, Papke T, Merklein M, Drummer D (2021) Fibre orientation mechanism of fibre reinforced 
thermoplastics hybrid parts joined with metallic pins. Appl Compos Mater. https://doi.org/10.1007/s10443-021-09892-0

14. Mattner T, Wrensch M, Drummer D (2020) Shear behaviour of woven and non-crimp fabric based thermoplastic composites at near-processing conditions. Compos Part B 185:107761

15. Ehrenstein GW (2006) Verstärkungsfasern. In: Ehrenstein GW (ed) Faserverbund-Kunststoffe, 2nd edn. Carl Hanser, München, pp 19-49

16. Deutscher Verband für Schweißen und Verwandte Verfahren (2007) DVS/EFB 3480-1 testing of properties of joints: testing of properties of mechanical and hybrid (mechanical/bonded) joints, DVS media GmBH. Beuth-Verlag GmbH, Düsseldorf
17. Hufenbach AW, Kupfer R, Hornig A (2012) Thermoactivated pinning: a novel joining technique for thermoplastic composites. Solid State Phenom 188:176-181

18. Kupfer T (2016) Zur Warmlochformung in Textil-ThermoplastStrukturen-Technologie, Phänomologie, Modellierung, PhD Thesis, Fakultät für Maschinenwesen, Technische Universität Dresden

Publisher's Note Springer Nature remains neutral with regard to jurisdictional claims in published maps and institutional affiliations. 